\title{
İlkokul Öğrencilerinin “Varlıkların Hareket Özellikleri" Konusunda Öğrendikleri Bilgileri Günlük Hayat İle İlişkilendirme Durumları
}

\author{
DOI: $10.26466 /$ opus.826004 \\ $*$
}

\section{Sümeyye Aydın Gürler *}

* Dr. Öğr. Üyesi, Gaziantep Üniversitesi, Nizip Eğitim Fakültesi, Gaziantep/Türkiye

E-Posta: s.aydingurler@gmail.com

ORCID: $\underline{0000-0003-2651-4395}$

\section{Öz}

Fen bilimleri dersindeki soyut ve karmaşık kavramlarm henüz soyut düşünme becerisi yeterince gelişmemiş olan ilkokul öğrencilerine öğretilmesi diğer kademelere göre daha zordur. Dolayısıyla bu kavramların somutlaştırllarak öğrenciye verilmesi gerekmektedir. Bunu sağlamanın bir yolu da soyut kavramların günlük hayat ile ilişsilendirilerek öğrenciye verilmesidir. Bu çalışmada da ilkokul öğrencilerinin "Varlıkların Hareket Özellikleri" konusunda öğrendikleri bilgileri günlük hayat ile ilişkilendirme durumlarının belirlenmesi amaçlanmıştır. Araştırma verileri 2019-2020 eğitim-öğretim yıl içerisinde elde edilmiş olup, çalışma grubu ise Gaziantep ili Nizip ilçesinin farklı ilkokullarında öğrenim gören 100 üçüncü sınıföğrencisinden oluşmuştur. Veri toplama aracı olarak beş açık uçlu sorudan oluşan bir anket kullanılmıştır. Çalışma nitel olarak tasarlanmış olup, çalışmada özel durum yöntemi kullanılmıştır. Veri analizi olarak ise betimsel analiz yöntemi kullanılmıştır. Çalışmada ilkokul üçüncü sınıföğrencilerinin "Varlıkların Hareket Özellikleri" konusunda öğrendikleri temel kavramları günlük hayat ile ilişkilendirebildikleri ancak bu ilişkilendirmenin istenilen seviyede olmadığı sonucuna ulaşılmıştır. Ayrıca alan yazında yapılan benzer çalışmalardan elde edilen sonuçların aksine yapılan çalışmada öğrencilerin önemli bir kavram yanılgısı yaşamadıkları görülmüştür. Elde edilen sonuçlar doğrultusunda ise bazı önerilerde bulunulmuştur.

Anahtar Kelimeler: Günlük hayat, ilişkilendirme, ilkokul öğrencisi. 


\title{
Primary School Students' Association Levels between Daily Life and the Acquired Knowledge on "Motion of Assets"
}

\begin{abstract}
It is more difficult to teach the abstract and complex concepts in science course to primary school students whose abstract thinking abilities have not yet been fully developed in comparison with students in other grades. Hence, it is necessary to transform such abstract concepts into concrete ones in order to teach them to the student. Associating abstract concepts with daily life is one of the methods for accomplishing this. The aim of the present study is to examine primary school students' association levels between daily life and the acquired knowledge on "Motion of Assets". The study data were acquired during 2019-2020 academic year with the study group comprised of 100 third grade students at different primary schools in the Nizip district of the Gaziantep province. A survey consisting of five open ended questions was used for data acquisition. The study was designed as a qualitative study with case study method applied. Descriptive analysis method was used for data analysis. It was concluded as a result of the study that third grade students can associate the fundamental knowledge acquired on the "Motion of Assets" with daily life but that the level of association is not at the desired level. In addition, it was also observed contrary to results of similar previous studies that the students have not experienced a significant misconception. Various suggestions have been made in accordance with the acquired results.
\end{abstract}

Keywords: Daily life, association, primary school student. 


\section{Giriş}

Toplumların çoğunda toplum kültürü ile bilimsel kültür arasında boşluklar vardır (Ash, 2004). Oysaki öğrencilerin sınıfta öğrendikleri birçok bilimsel bilgi aslında öğrencilerin günlük hayatlarında sık sık karşılaştıkları olaylarla örtüşmektedir. Öğrencilerin okulda öğrendikleri bilgiler ile kendi hayatlarını etkileyen olaylar arasındaki ilişkileri kavramaları, onların bilimsel okuryazar bir birey olmalarına büyük oranda katkı sağlamaktadır (Balkan Kıyıcı ve Aydoğdu, 2011). Bilişsel alan kuramcılarına göre öğrenilen bilgilerin günlük yaşam ile ilişkilendirilmesi bilginin içselleştirilmesi bakımından önemlidir (Aydın, 2000; Senemoğlu, 2001). Yani öğrencilerin okul ortamında öğrendikleri bilgileri günlük yaşamda karşılaştıkları durumlara uyarlayabilmeleri hem onların hayatını kolaylaştırır hem de öğrendikleri bilgileri özümsemelerini sağlar (Pınarbaşı, Doymuş, Canpolat ve Bayrakçeken, 1998). Bir öğretmen öğrencilerine bilgiyi doğrudan vererek ezberlemelerini sağlamak yerine, öğrencilerine araştırarak bilgiye ulaşma yolunu öğretmeli ve bunu yaparken de bu bilgilerin günlük hayatta kullanabilmesini sağlamalıdır (Buyruk ve Korkmaz, 2016). Öğrenci okulda öğrendiği bilgiyi günlük hayat ile ne kadar çok ilişkilendirebiliyorsa öğrenilen bilgiler ezberden uzak dolayısıyla kalıcı olur (Özmen, 2003). Öğrencilerin sahip oldukları bilgileri günlük hayatta karşılaştıkları durumlara uyarlamaları onların olayları daha iyi anlamalarına, çevreye karşı daha bilinçli olmalarına ve günlük hayata daha uyumlu bireyler olmaları yönünde birçok katkı sağlayacaktır (Pınarbaşı ve diğ., 1998). Öğrencilerin okul ortamında öğrendikleri bilgileri günlük yaşama transfer etmelerine katkı sağlayacak derslerin başında fen bilimleri dersi gelmektedir. Çünkü fen derslerinin içeriğine bakıldığında, neredeyse tamamına yakın kısmının günlük yaşamla ilişkili olduğu görülmektedir (Enginar, Saka ve Sesli, 2002). Dolayısıyla öğrencilerin günlük yaşam ile okulda öğrendikleri bilgiler arasında ilişki kurmaları fen eğitiminin en temel amaçlarından biri olmuştur (İlkörücü-Göçmençelebi ve Özkan, 2009). Fen okuryazar birey yetiştirebilmek için bireylerin sadece alanla ilgili ilke ve kavramları çok iyi bilmesi değil, aynı zamanda bireylerin öğrendikleri bilgileri günlük yaşamlarında da kullanması istenmektedir (Yılmaz, 2008). Öğrencilerin sahip olduğu fen bilgilerinin sadece ders kitaplarıyla sınırlandırılması sonucu öğrenciler öğrendiği bilgileri günlük yaşam ile ilişkilendirmekte zorlanmaktadır (Türkoğuz ve Yankayış, 2015). Balkan Kıyıcı ve Aydoğdu (2011)'ya göre okullarda verilen 
fen eğitimi ile öğrencilere sadece teorik bilgi değil, aynı zamanda günlük hayatta karşılaşabilecekleri problemlere mantıklı ve yaratıcı çözümler önerebilmelerini sağlayacak bilgiler de verilmelidir. Bunu sağlamanın yolu da öğrencilerin okulda öğrendikleri bilgileri günlük yaşamda karşılaştıkları olaylarla bağdaştırabilmektir (Ayas ve Özmen, 1998). Öğrencilerin fen derslerine karşı olumsuz tutum sergilemelerinin ve genelde bu derste başarısız olmalarının bir sebebi de; fen konularının karmaşık ve soyut olmasının yanı sıra bu konuların aktarımının da soyut olarak yapılması, yani konu aktarımı yaparken günlük hayattan yeteri kadar örnek verilmemesi olarak görülmektedir (Yiğit, Devecioğlu ve Ayvacı, 2002). Fen eğitiminde kavramlar günlük hayat ile ilişkilendirilerek verildiğinde, öğrencilerin fen derslerine karşı daha fazla ilgi gösterdiği, etkili öğrenmenin gerçekleştiği, derslerin daha eğlenceli olduğu dolayısıyla öğrencilerde fen derslerine karşı olumlu tutum geliştiği görülmüştür (Andree, 2003; Fortus vd., 2005). Dolayısıyla öğrencilerin bu derste öğrendikleri konuların ve bilgilerin okul dışı ortamlarda da yaparak-yaşayarak deneyim kazandırılması ve böylece öğrenilenlerin pekiştirilmesi bilginin kalıcılığı bakımından günümüzde önemli görülmektedir (Şimşek, 2011). İlkokul ve ortaokul fen bilimleri dersi birbiriyle bağlantılı olup sarmal bir yapıya sahiptir. Bu bağlantılarda oluşan kopukluk, öğrencilerin hazırbulunuşlukların olumsuz olarak etkileyeceğinden bir sonraki öğrenmeleri de olumsuz olarak etkilenecektir. Soyut düşünme becerisi yeterince gelişmemiş olan ilkokul öğrencileri için fen bilimleri dersinde yer alan karmaşık ve soyut kavramların ögretilmesi diğer kademelere göre daha zordur. Dolayısıyla bu öğrenciler için bu kavramların somutlaştırılarak verilmesi büyük öneme sahiptir. Bunu sağlamanın yolu da bu soyut kavramların günlük yaşam ile ilişkilendirilerek öğrenciye aktarılmasıdır. Alan yazın incelendiğinde, ülkemizde öğrencilerin sahip oldukları fen bilgilerini günlük yaşam ile hangi düzeyde ilişkilendirebildiklerine dair birçok çalışma (Acet, 2019; Akgün, Tokur ve 2016; Balkan Kıyıcı ve Aydoğdu, 2011; Buyruk ve Korkmaz, 2016; Çelikler ve Kara, 2016; Doğan, Kırvak ve Baran, 2004; Kara, 2016; Köse ve Gül, 2016; İlkörücü-Göçmençelebi ve Özkan, 2010; Taşdemir ve Demirbaş, 2010) yapıldığı görülmektedir. Ancak bu çalışmaların ortaokul ve lise öğrencileri veya öğretmen adaylarıyla yapıldığı göze çarpmaktadır. Bununla beraber ilkokul öğrencilerinin sahip oldukları fen bilgilerinin günlük hayat ile ilişkilendirme düzeyini belirlemeye yönelik tek bir çalışmaya rastlanılmıştır (Alkış Küçü- 
kaydın, 2019). Bununla birlikte, yapılan alan yazı taramasından ilkokul öğrencilerinin ilkokul fen bilimleri dersinde seçilen bir konuda öğrendikleri bilgileri günlük hayata aktarma düzeyini belirlemeye yönelik bir çalışmaya ise rastlanılmamıştır. Dolayısıyla bu çalışmanın alana büyük katkı getireceği düşünülmektedir. Bu bağlamda, bu çalışmada ilkokul 3. sınıf öğrencilerinin "Varlıkların Hareket Özellikleri" konusunda öğrendikleri bilgileri günlük hayat ile ilişkilendirme durumları belirlenmeye çalışılmıştır. Bu amaçla oluşturulan çalışmanın alt problemleri şunlardır:

1. Canl veya cansiz varliklarm hizlarm artırarak hareket etmelerine hizlanma hareketi denir. Günlük hayatta karşılaştığınız hızlanma hareketlerine örnekler verebilir misiniz?

2. Canlı veya cansiz varlklarm hızlarm azaltarak hareket etmelerine yavaşlama hareketi denir. Günlük hayatta karşılaştığınız yavaşlama hareketlerine örnekler verebilir misiniz?

3. Yön değiştirme hareketi, hareket halinde olan bir cismin mevcut hareketinden farklı bir yönde ve bir kuvvete maruz kalarak farklı bir yöne doğru yönelmesidir. Günlük hayatta karşılaştı̆̆ınız yön değiştirme hareketlerine örnekler verebilir misiniz?

4. Bir cismin belli bir nokta etrafinda dolanmasina dönme hareketi denir. Günlük hayatta karşılaştığınız dönme hareketlerine örnekler verebilir misiniz?

5. Hareketli bir varlığın peş peşe aşă̆g-yukan veya ileri geri yönde tekrarlayarak yaptı̆̆ı harekete sallanma hareketi denir. Günlük hayatta karşılaştığınız sallanma hareketlerine örnekler verebilir misiniz?

\section{Yöntem}

Bu çalışma nitel olarak tasarlanmış olup çalışmada özel durum yöntemi kullanılmıştır. Özel durum yöntemi, nitel araştırma yaklaşımlarının sahip olduğu özellikleri taşıyan bir araştırma yöntemidir (Çepni, 2007). "Örnek olay", "vaka çalışması" gibi farklı isimlerle de adlandırılan özel durum yöntemi önceleri daha çok antropoloji ve sosyoloji alanlarında kullanılırken son zamanlarda eğitim alanında kullanılmaya başlanmıştır (Ekiz, 2003). Özel durum yönteminin en önemli özelliği; özel bir durumun üzerine yoğunlaşma fırsatı vererek problemin hem derinlemesine hem de kısa sürede çalışılmasına imkân vermesidir (Çepni, 2007; Wellington, 2000). Bu yöntem, bir durumu bütün yönleriyle ele alan bir yöntem olup bir durum hakkında detaylı 
bilgi elde etmek ve "nasıl" sorusuna cevap aramak için kullanılmaktadır (Çepni, 2009; Karasar, 2005). İncelenecek durum bazen bir kişi, bazen bir öğrenci bazen de bir okul olabilir (Denscombe, 1998). Dolayısıyla bu çalışmada, ilkokul öğrencilerinin "Varlıkların Hareket Özellikleri” konusunda öğrendikleri bilgileri günlük hayat ile nasıl ilişkilendirdiklerinin ortaya çıarılması amaçlandığından özel durum yönteminin kullanılması uygun görülmüştür.

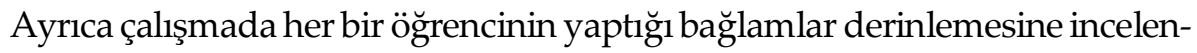
miş ve her bir öğrenci ayrı bir özel durum olarak görülmüştür.

\section{Çalışma grubu}

Araştırma verileri, 2019-2020 eğitim-öğretim yılı içerisinde toplanmıştır. Çalışma grubu ise Gaziantep ili Nizip ilçesinin farklı ilkokullarında öğrenim gören 100 üçüncü sınıf öğrencisinden oluşmaktadır. Çalışma grubunun belirlenmesinde amaçsal örnekleme yaklaşımlarından tipik durum örnekleme yöntemi kullanılmıştır. Bu örnekleme yönteminde, araştırılan problem ile ilgili evrende var olan çok sayıdaki durumdan tipik durumlar seçilerek bu gruplar üzerinden veri toplanır (Büyüköztürk, K1lıç Çakmak, Akgün, Karadeniz ve Demirel, 2009). Tipik durum, toplum içerisinde ortalama olarak kabul edilen ve sıra dışı olmayan durumdur (Patton, 2005). Örneğin okullar üzerinde yapılacak bir araştırma için tipik durum örneklemesi, şehir merkezinde göreceli olarak geneli yansitabilecek birkaç okulun seçilmesi ile olabilir (Strauss ve Corbin, 2014). Ancak burada dikkat edilmesi gereken örnekleme alınacak okulların birçok özellik bakımından (fiziksel yapı, başarı durumları gibi) sıradan ve tipik durumda olmasıdır (Büyüköztürk, Kılıç Çakmak, Akgün, Karadeniz ve Demirel, 2009). Bu amaçla bu çalışmada, ilçe merkezinde bulunan ve fiziksel yapısı, imkânları ve başarı düzeyi bakımından orta düzeyde olan beş ilkokul seçilmiştir. Çalışmaya katılan öğrencilerin $44^{\prime}$ ü kız, 56'sı erkek olup yaşları 8 ile 10 arasında değişmektedir.

\section{Veri toplama arace}

Veri toplama aracı olarak araştırmacı tarafından hazırlanan ve beş açık uçlu sorudan oluşan bir anket kullanılmıştır. Bu anket ile 3. sınıf öğrencilerinin fen bilimleri dersinde "Varlıkların Hareket Özellikleri" konusunda öğrendikleri bilgileri günlük hayat ile ilişkilendirme düzeyleri belirlenmeye çalışılmıştır. Özellikle bu konunun seçilmesinin nedeni bu konuda yer alan kavramların 
günlük hayatta öğrencilerin sık sık karşılaştığı kavramlar olmasıdır. Anket soruları hazırlanmadan önce, öncelikle araştırmacı tarafından araştırma konusu ile ilgili alan yazı taraması yapılmış ve 3. sınıf fen bilimleri ders kitabında yer alan "Varlıkların Hareket Özellikleri" konusu detaylı bir şekilde incelenerek anket soruları hazırlanmıştır. Ayrıca bu sorular hazırlanırken 2018 Fen Bilimleri Dersi Öğretim Programının özel amaçlarından biri olan "tüm bireylerin günlük yaşam sorunlarına ilişkin sorumluluk almasını ve bu sorunları çözmede fen bilimlerine ilişkin bilgi, bilimsel süreç becerileri ve diğer yaşam becerilerinin kullanılmasını sağlamak" teması göz önünde bulundurulmuştur (Milli Eğitim Bakanlığı [MEB], 2018). Anketin kapsam geçerliği için iki alan eğitimi uzmanının ve iki sınıf öğretmeninin görüşleri alınmıştır. Bununla birlikte anket sorularının okunabilirliği ve anlaşılabilirliği bakımından dört 3. sınıf öğrencisi ile ön uygulama gerçekleştirilmiştir. Gelen dönütler doğrultusunda anket sorularında düzenlemeler yapılarak anket uygulamaya hazır hale getirilmiştir.

\section{Verilerin analizi}

Çalışma verileri betimsel analiz yöntemi kullanılarak analiz edilmiştir. Bu analiz yönteminde çeşitli veri toplama teknikleri ile toplanan veriler daha önceden belirlenen temalara uygun olarak özetlenir ve yorumlanır (Yildırım ve Şimşek, 2003). Ayrıca bu analiz yöntemi, kişilerin söyledikleri ifadelerin okuyucuya direkt aktarılmasına fırsat verir (Çepni, 2010). Yapılan bu çalışmada betimsel analiz dört aşamadan oluşmuştur (Yıldırım ve Şimşek, 2008). İlk aşamada araştırma sorularına dayanarak veri analizi için bir çerçeve oluşturulmuştur. Böylece verilerin hangi temalar altında yer alacağ belirlenmiştir. İkinci aşamada ise oluşturulan çerçeveye göre veriler anlamlı ve mantıklı bir şekilde bir araya getirilmiştir. Üçüncü aşamada araştırmacı tarafından düzenlenen veriler tanımlanmıştır. Ayrıca bu aşamada öğrencilerin günlük yaşamdan verdikleri örnekler üzerinde sadece gerekli düzenlemeler (imla hatası, yazım yanlışı gibi) yapılmış ve alıntı şeklinde frekans sıklıkları hesaplanmıştır. En son aşamada ise araştırmacı tarafından bulgular açıklanmış, ilişkilendirilmiş ve anlamlandırılmıştır (Yıldırım ve Şimşek, 2003). 


\section{Araştırmanın Etik İzinleri}

Yapılan bu çalışmada "Yükseköğretim Kurumları Bilimsel Araştırma ve Yayın Etiği Yönergesi” kapsamında uyulması belirtilen tüm kurallara uyulmuştur. Yönergenin ikinci bölümü olan "Bilimsel Araştırma ve Yayın Etiğine Aykırı Eylemler" başlığı altında belirtilen eylemlerden hiçbiri gerçekleştirilmemiştir.

\section{Etik Kurul İzin Bilgileri}

Etik değerlendirmeyi yapan kurul ad $1=$ Gaziantep Üniversitesi Sosyal ve Beşeri Bilimler Etik Kurulu

Etik değerlendirme kararının tarihi= 22.07.2020

Etik değerlendirme belgesi sayı numarası $=34306$

\section{Bulgular}

Çalışma bulguları açık uçlu anket sorularından elde edilen verilerin çözümlenmesi ile elde edilmiştir. Çözümlenen veriler ise tablolar haline getirilerek gerekli açıklamalar ile birlikte sunulmuştur.

Çalışmaya katılan öğrencilere çalışmanın ilk sorusu olarak "Canlı veya cansız varlkklarm hizların artırarak hareket etmelerine hızlanma hareketi denir. Günlük hayatta karşılaştığını hızlanma hareketlerine örnekler verebilir misiniz?" sorusu sorulmuştur. Öğrencilerin bu soruya verdikleri cevaplara ilişkin frekans değerleri Tablo 1' de verildiği gibidir.

Tablo 1. Günlük hayatta karşılaşılan hızlanma hareketleri

\begin{tabular}{lll}
\hline Günlük hayattan örnekler & $\mathrm{f}$ & $\%$ \\
\hline Kaplan gören ceylan & 1 & 1 \\
\hline Havadan düşen top & 8 & 8 \\
\hline Havalanan uçak & 19 & 19 \\
\hline Yeşil ışıkta kalkan araba & 10 & 10 \\
\hline Yere atılan kalem & 1 & 1 \\
\hline Kaydıraktan kayan çocuk & 4 & 4 \\
\hline Acele eden insan & 3 & 3 \\
\hline Duraktan kalkan otobüs & 8 & 8 \\
\hline Gazına basılan araba & 9 & 9 \\
\hline Koşmaya başlayan insan & 23 & 23 \\
\hline Daldan düşen elma & 2 & 2 \\
\hline Uçan kuş & 1 & 1 \\
\hline Kemik gören köpek & 6 & 6 \\
\hline
\end{tabular}




\begin{tabular}{lll}
\hline Vurulan top & 10 & 10 \\
\hline Limandan kalkan gemi & 1 & 1 \\
\hline Uzaya firlatılan füze & 2 & 2 \\
\hline Yıldız kayması & 2 & 2 \\
\hline Fare yakalamak isteyen kedi & 1 & 1 \\
\hline Mutfak robotunun kademesinin artırlması & 1 & 1 \\
\hline Uçurumdan yuvarlanan top & 2 & 2 \\
\hline Yaydan çıkan ok & 1 & 1 \\
\hline Yavrusunu kurtarmaya çalışan kuş & 1 & 1 \\
\hline Uçurumdan düşen taş & 1 & 1 \\
\hline İtilen oyuncak araba & 4 & 4 \\
\hline Lunaparkta çarpışan araba & 1 & 1 \\
\hline İtilen market arabası & 2 & 2 \\
\hline Düşen yağmur damlası & 1 & 1 \\
\hline Göktaşı düşmesi & 1 & 1 \\
\hline Geyik gören çita & 3 & 3 \\
\hline Peynir gören fare & 1 & 1 \\
\hline
\end{tabular}

Tablo 1 incelendiğinde, öğrencilerin günlük yaşamdan verdikleri hızlanma hareketi örnekleri; kaplan gören ceylan (\%1), havadan düşen top (\%8), havalanan uçak (\%19), yeşil ışıkta kalkan araba (\%10), yere atılan kalem (\%1), kaydıraktan kayan çocuk (\%4), acele eden insan (\%3), duraktan kalkan otobüs (\%8), gazına basılan araba (\%9), koşmaya başlayan insan (\%23), daldan düş̧en elma (\%2), uçan kuş (\%1), kemik gören köpek (\%6), vurulan top (\%10), limandan kalkan gemi (\%1), uzaya fırlatılan füze (\%2), yıldız kayması (\%2), fare yakalamak isteyen kedi (\%1), mutfak robotunun kademesinin art1rılması (\%1), uçurumdan yuvarlanan top (\%2), yaydan çıkan ok (\%1), yavrusunu kurtarmaya çalışan kuş (\%1), uçurumdan düşen taş (\%1), itilen oyuncak araba (\%4), lunaparkta çarpışan araba (\%1), itilen market arabası (\%2), düşen yağmur damlası (\%1), göktaşı düşmesi (\%1), geyik gören çita (\%3) ve peynir gören fare (\%1) şeklinde dağılım göstermektedir.

Çalışmaya katılan öğrencilere çalışmanın ikinci sorusu olarak "Canlı veya cansiz varlklarm hizlarm azaltarak hareket etmelerine yavaşlama hareketi denir. Günlük hayatta karşılaştığını yavaşlama hareketlerine örnekler verebilir misiniz?" sorusu sorulmuştur. Öğrencilerin bu soruya verdikleri cevaplara ilişkin frekans değerleri Tablo 2' de verildiği gibidir. 
Tablo 2. Günlük hayatta karşılaşılan yavaşlama hareketleri

\begin{tabular}{lll}
\hline Günlük hayattan örnekler & $\mathrm{f}$ & $\%$ \\
\hline İstasyona yaklaşan tren & 8 & 8 \\
\hline Fişi çekilen mutfak robotunun yavaşlaması & 1 & 1 \\
\hline Frenine basılan araba & 19 & 19 \\
\hline Kirmızı ışı̆̆a yaklaşan araba & 22 & 22 \\
\hline Fişi çekilen makine & 1 & 1 \\
\hline Rampa çıkılması & 3 & 3 \\
\hline Durağa yaklaşan otobüs & 11 & 11 \\
\hline Piste iniş yapan uçak & 10 & 10 \\
\hline Direğe çarpan top & 1 & 1 \\
\hline Bitiş çzgisine yaklaşan koşucu & 2 & 2 \\
\hline Havalanmaya başlayan uçak & 1 & 1 \\
\hline Koşan köpeğin tasmasından çekilmesi & 1 & 1 \\
\hline Park edilmeye çalışıllan araba & 1 & 1 \\
\hline Koşan çocuğun geriye doğru çekilmesi & 1 & 1 \\
\hline Okula geç kalan çocuğun okulu görünce yavaşlaması & 1 & 1 \\
\hline Havaya atılan top & 5 & 5 \\
\hline Önüne araba çıkan çocuk & 1 & 1 \\
\hline Pili azalan saatte akrebin yavaşlaması & 1 & 1 \\
\hline Yere konan kelebek & 1 & 1 \\
\hline Bir yere konan kuş & 2 & 2 \\
\hline Çamaşır sikma programının sonuna gelinmesi & 1 & 1 \\
\hline Limana yaklaşan gemi & 2 & 2 \\
\hline Koşarken önümüze engel çıkılması & 1 & 1 \\
\hline Benzini biten araba & 1 & 1 \\
\hline
\end{tabular}

Tablo 2 incelendiğinde, öğrencilerin günlük yaşamdan verdikleri yavaşlama hareketi örnekleri; istasyona yaklaşan tren (\%8), fişi çekilen mutfak robotunun yavaşlaması (\%1), frenine basılan araba (\%19), kırmızı ışığa yaklaşan araba (\%22), fişi çekilen makine (\%1), rampa çıkılması (\%3), durağa yaklaşan otobüs (\%11), piste iniş yapan uçak (\%10), direğe çarpan top (\%1), bitiş çizgisine yaklaşan koşucu (\%2), havalanmaya başlayan uçak (\%1), koşan köpeğin tasmasından çekilmesi (\%1), park edilmeye çalışılan araba (\%1), koşan çocuğun geriye doğru çekilmesi (\%1), okula geç kalan çocuğun okulu görünce yavaşlaması (\%1), havaya atılan top (\%5), önüne araba çıkan çocuk (\%1), pili azalan saatte akrebin yavaşlaması (\%1), yere konan kelebek (\%1), bir yere konan kuş (\%2), çamaşır sıkma programının sonuna gelinmesi (\%1), limana yaklaşan gemi (\%2), koşarken önümüze engel çıkılması (\%1) ve benzini biten araba (\%1) şeklinde dağılım göstermektedir. 
Çalışmaya katılan öğrencilere çalışmanın üçüncü sorusu olarak "Yön değiştirme hareketi, hareket halinde olan bir cismin mevcut hareketinden farkl yönde ve bir kuvvete maruz kalarak farkh bir yöne doğru yönelmesidir. Günlük hayatta karşılaştığını yön değiştirme hareketlerine örnekler verebilir misiniz?" sorusu sorulmuştur. Öğrencilerin bu soruya verdikleri cevaplara ilişkin frekans değerleri Tablo 3' de verildiği gibidir.

Tablo 3. Günliuk hayatta karşılaşılan yön değiştirme hareketleri

\begin{tabular}{|c|c|c|}
\hline Günlük hayattan örnekler & $\mathrm{f}$ & $\%$ \\
\hline Direksiyonu çevrilen araba & 6 & 6 \\
\hline Yandan vurulan oyuncak araba & 3 & 3 \\
\hline Ters yönde kuvvet uygulanan araba & 1 & 1 \\
\hline Duvara ve direğe çarpan top & 17 & 17 \\
\hline İnsana çarpan top & 2 & 2 \\
\hline Kavşaktan dönen araba & 17 & 17 \\
\hline Tenis oynarken pinpon topunun yaptığı hareket & 4 & 4 \\
\hline Sallanan salıncak & 1 & 1 \\
\hline Havalimanına yaklaşan uçak & 1 & 1 \\
\hline Direksiyonu çevrilen bisiklet & 1 & 1 \\
\hline Kediyi gören farenin yön değiştirmesi & 1 & 1 \\
\hline Çitanın kovaladığı geyik & 1 & 1 \\
\hline Drift atan araba & 1 & 1 \\
\hline Ay çiçeğinin Güneş'e yönelmesi & 3 & 3 \\
\hline Paslaşılan topun yaptığ1 hareket & 5 & 5 \\
\hline Sağa dönen araba & 8 & 8 \\
\hline Önüne araba çıan adam & 1 & 1 \\
\hline İp atlarken & 1 & 1 \\
\hline Gondolun yaptığı hareket & 1 & 1 \\
\hline Yakan top oynarken & 1 & 1 \\
\hline Ambulans gören arabanın sağ şeride geçmesi & 1 & 1 \\
\hline Köpek gören çocuk & 1 & 1 \\
\hline Kaydıraktan kayarken & 2 & 2 \\
\hline U dönüşü yapan araba & 2 & 2 \\
\hline Dönen sandalye & 3 & 3 \\
\hline Düz giden birinin markete doğru yönelmesi & 1 & 1 \\
\hline Araba görünce kaçan kedi & 1 & 1 \\
\hline Dünyanın Güneş etrafında dönmesi & 1 & 1 \\
\hline Saatin hareketi & 1 & 1 \\
\hline İnsanların sağa veya sola dönmesi & 2 & 2 \\
\hline Düz giden bilyenin rüzgâr etkisi ile yönünün değişmesi & 1 & 1 \\
\hline
\end{tabular}


Tablo 3 incelendiğinde, öğrencilerin günlük yaşamdan verdikleri yön değiştirme hareketi örnekleri; direksiyonu çevrilen araba (\%6), yandan vurulan oyuncak araba (\%3), ters yönde kuvvet uygulanan araba (\%1), duvara ve direğe çarpan top (\%17), insana çarpan top (\%2), kavşaktan dönen araba (\%17), tenis oynarken pinpon topunun yaptığı hareket (\%4), sallanan salıncak (\%1), havalimanına yaklaşan uçak (\%1), direksiyonu çevrilen bisiklet (\%1), kediyi gören farenin yön değiştirmesi (\%1), çitanın kovaladı̆̆ı geyik (\%1), drift atan araba (\%1), Ay çiçeğinin Güneş'e yönelmesi (\%3), paslaşılan topun yaptığ1 hareket (\%5), sağa dönen araba (\%8), önüne araba çıan adam (\%1), ip atlarken (\%1), gondolun yaptığ lans gören arabanın sağ şeride geçmesi (\%1), köpek gören çocuk (\%1), kayd1raktan kayarken (\%2), U dönüşü yapan araba (\%2), dönen sandalye (\%3), düz giden birinin markete doğru yönelmesi (\%1), araba görünce kaçan kedi (\%1), Dünyanın Güneş etrafında dönmesi (\%1), saatin hareketi (\%1), insanların sağa veya sola dönmesi (\%2) ve düz giden bilyenin rüzgâr etkisi ile yönünün değişmesi (\%1) şeklinde dağılım göstermektedir.

Çalışmaya katılan öğrencilere çalışmanın dördüncü sorusu olarak "Bir cismin belli bir nokta etrafinda dolanmasina dönme hareketi denir. Günlük hayatta karşllaştığınız dönme hareketlerine örnekler verebilir misiniz?" sorusu sorulmuştur. Öğrencilerin bu soruya verdikleri cevaplara ilişkin frekans değerleri Tablo 4 ' de verildiği gibidir.

\section{Tablo 4. Günlük hayatta karşılaşılan dönme hareketleri}

\begin{tabular}{lll}
\hline Günlük hayattan örnekler & $\mathrm{f}$ & $\%$ \\
\hline Dönme dolap & 42 & 42 \\
\hline Mevlana & 3 & 3 \\
\hline Musluğu açma & 6 & 6 \\
\hline Balerinin dönmesi & 3 & 3 \\
\hline Hortum olayı & 6 & 6 \\
\hline Mutfak robotunun dönmesi & 1 & 1 \\
\hline Arabanın tekeri & 5 & 5 \\
\hline Dünya'nnn kendi etrafinda dönmesi & 16 & 16 \\
\hline Semazenlerin dönmesi & 13 & 13 \\
\hline Rüzgâr türbini & 2 & 2 \\
\hline Kavanozun kapağı açıllrken yapılan hareket & 1 & 1 \\
\hline Atllkarınca & 12 & 12 \\
\hline Vantiläör pervanesi & 16 & 16 \\
\hline Helikopter pervanesi & 3 & 3 \\
\hline Parktaki dönence & 1 & 1 \\
\hline Saatin yelkovanı & 9 & 9 \\
\hline Dönen topaç & 11 & 11 \\
\hline
\end{tabular}




\begin{tabular}{lll}
\hline Dünyanın Güneş etrafında yaptığı hareket & 4 & 4 \\
\hline Pergeldeki kalemin iğne etrafında yaptı̆̆ı hareket & 1 & 1 \\
\hline Kutu kutu pense oyunu & 1 & 1 \\
\hline Bisikletin pedalının çevrilmesi & 1 & 1 \\
\hline Çamaşır makinesi & 2 & 2 \\
\hline Çarkıfeleğin dönmesi & 3 & 3 \\
\hline Kalemin açacakla açılması & 1 & 1 \\
\hline Pusulanın ibresi & 2 & 2 \\
\hline Matkabın dönmesi & 1 & 1 \\
\hline
\end{tabular}

Tablo 4 incelendiğinde, öğrencilerin günlük yaşamdan verdikleri dönme hareketi örnekleri; dönme dolap (\%42), Mevlana (\%3), musluğu açma (\%6), balerinin dönmesi (\%3), hortum olayı (\%6), mutfak robotunun dönmesi (\%1), arabanın tekeri (\%5), Dünya'nın kendi etrafında dönmesi (\%16), Semazenlerin dönmesi (\%13), rüzgâr türbini (\%2), kavanozun kapağı açılırken yapılan hareket (\%1), atlıkarınca (\%12), vantilatör pervanesi (\%16), helikopter pervanesi (\%3), parktaki dönence (\%1), saatin yelkovanı (\%9), dönen topaç (\%11), Dünyanın Güneş etrafında yaptığ rafında yaptığı hareket (\%1), kutu kutu pense oyunu (\%1), bisikletin pedallnın çevrilmesi (\%1), çamaşır makinesi (\%2), çarkıfeleğin dönmesi (\%3), kalemin açacakla açılması (\%1), pusulanın ibresi (\%2) ve matkabın dönmesi (\%1) şeklinde dağılım göstermektedir.

Çalışmaya katılan öğrencilere çalışmanın son sorusu olarak "Hareketli bir varlı̆̆ın peş peşe aşă̆ı-yukarı veya ileri-geri yönde tekrarlayarak yaptığı harekete sallanma hareketi denir. Günlük hayatta karşılaştığını sallanma hareketlerine örnekler verebilir misiniz?" sorusu sorulmuştur. Öğrencilerin bu soruya verdikleri cevaplara ilişkin frekans değerleri Tablo 5’ de verildiği gibidir.

Tablo 5. Günlük hayatta karşılaşılan sallanma hareketleri

\begin{tabular}{lll}
\hline Günlük hayattan örnekler & $\mathrm{f}$ & $\%$ \\
\hline Asansörün aşağı-yukarı hareketi & 3 & 3 \\
\hline Salıncakta sallanan çocuk & 76 & 76 \\
\hline Gondolun sallanması & 3 & 3 \\
\hline Sallanan sandalye & 6 & 6 \\
\hline Yelpazenin sallanması & 2 & 2 \\
\hline Vurulan boks torbası & 2 & 2 \\
\hline Guguklu saat & 3 & 3 \\
\hline Bayrağın sallanması & 3 & 3 \\
\hline Dişin sallanması & 1 & 1 \\
\hline İpe asılarak sallanan sirkteki gösterici & 4 & 4 \\
\hline Saat sarkacı & 8 & 8 \\
\hline Kilise çanının sallanması & 1 & 1 \\
\hline
\end{tabular}




\begin{tabular}{lll}
\hline İpe bağladığımız topacın sağa sola sallanması & 1 & 1 \\
\hline Hacıyatmazı ittiğimizde & 1 & 1 \\
\hline Tahterevalli & 8 & 8 \\
\hline Sallanan beşik & 11 & 11 \\
\hline Sallanan hamak & 1 & 1 \\
\hline Trambolinde zıplarken & 1 & 1 \\
\hline Klimanın kapağının aşăı yukarı hareketi & 1 & 1 \\
\hline Bebeğini ayağında sallayan anne & 1 & 1 \\
\hline Deprem anında evlerin hareketi & 7 & 7 \\
\hline Tespih sallamak & 2 & 2 \\
\hline Ütünün ileri geri hareketi & 1 & 1 \\
\hline
\end{tabular}

Tablo 5 incelendiğinde, öğrencilerin günlük yaşamdan verdikleri sallanma hareketi örnekleri; asansörün aşağı-yukarı hareketi (\%3), salıncakta sallanan çocuk (\%76), gondolun sallanması (\%3), sallanan sandalye (\%6), yelpazenin sallanması (\%2), vurulan boks torbası (\%2), guguklu saat (\%3), bayrağın sallanması (\%3), dişin sallanması (\%1), ipe asılarak sallanan sirkteki gösterici (\%4), saat sarkacı (\%8), kilise çanının sallanması (\%1), ipe bağladığ1mız topacın sağa sola sallanması (\%1), hacıyatmazı ittiğimizde (\%1), tahterevalli (\%8), sallanan beşik (\%11), sallanan hamak(\%1), Trambolinde ziplarken(\%1), klimanın kapağının aşağı yukarı hareketi (\%1), bebeğini ayağında sallayan anne (\%1), deprem anında evlerin hareketi (\%7), tespih sallamak (\%2) ve ütünün ileri geri hareketi (\%1) şeklinde dağılım göstermektedir.

\section{Tartışma ve Sonuç}

Bu çalışma ile ilkokul 3. sınıf öğrencilerinin "Varlıkların Hareket Özellikleri” konusunda öğrendikleri bilgileri günlük hayat ile ilişkilendirme durumları belirlenmeye çalışılmıştır. Çalışma bulguları incelendiğinde, çalışmaya katılan ilkokul öğrencilerinin "Varlıkların Hareket Özellikleri" konusunda yer alan kavramlarla ilgili çeşitli örnekler verdikleri görülmektedir. Bu duruma dayanarak ilkokul 3. sınıf öğrencilerinin "Varlıkların Hareket Özellikleri" konusunda öğrendikleri temel kavramları (hızlanma, yavaşlama, yön değiştirme, dönme, sallanma) günlük hayat ile ilişkilendirebildikleri söylenebilir. Ancak bu ilişkilendirmenin istenilen düzeyde olmadığı verilen örneklerden anlaşılmaktadır. Şöyle ki öğrenciler tarafından en çok söylenen hızlanma hareketi örneklerinin koşmaya başlayan insan (\%23), havalanan uçak (\%19), yeşil ışıkta kalkan araba (\%10) ve vurulan top (\%10) (Demiray ve Köker, 2017, s. 72); en çok söylenen yavaşlama hareketi örneklerinin kırmızı ışığa yaklaşan araba 
(\%22), frenine basılan araba (\%19), durağa yaklaşan otobüs (\%11) ve piste iniş yapan uçak (\%10) (Demiray ve Köker, 2017, s. 72); en çok söylenen dönme hareketi örneklerinin Dünya'nın kendi etrafinda dönmesi (\%16) ve dönen topaç (\%11) (Demiray ve Köker, 2017, s. 77); en çok söylenen sallanma hareketi örneğine salıncakta sallanan çocuk (\%76) (Demiray ve Köker, 2017 s.76) örneklerinin verilmesi ve tüm bu örneklerin öğrencilerin 3. sınıf fen bilimleri ders kitabında yer alan örneklerden oluşmasıdır. Ayrıca çok sık söylenmese de öğrenciler tarafından yön değiştirme hareketine verilen tenis oynarken pinpon topunun yaptığı hareket (\%4), Ayçiçeğinin Güneş'e yönelmesi (\%3) ve paslaşılan topun yaptığı hareket (\%5) (Demiray ve Köker, 2017, s. 74); dönme hareketine verilen bisiklet pedalının çevrilmesi (\%1) ve rüzgâr türbini (\%2) (Demiray ve Köker, 2017, s.77); sallanma hareketine verilen gondolun sallanması (\%3) ve tahterevalli (\%8) (Demiray ve Köker, 2017, s.76) örneklerinin de benzer şekilde öğrencilerin ders kitaplarında yer alan örnekler olduğu görülmektedir. "Varlıkların Hareket Özellikleri" ile ilgili günlük hayatta çok fazla sayıda örnek olmasına rağmen öğrencilerin daha çok ders kitaplarında yer alan örnekleri vermeleri sınıfta öğrenilen bazı bilgilerin daha çok ezberi bilgiler olarak kaldığına işaret etmektedir. Ayrıca bu durum, öğretmenlerin ders işlerken konuya ilişkin örnekleri daha çok ders kitaplarında yer alan örneklerle kısıtladıkları dolayısıyla günlük yaşamdan yeterince örnekler vermemelerinden kaynaklandığı söylenebilir. Oysaki günlük yaşamla ilişkilendirilmeden verilen bilgiler ezberi bir bilgi olmaktan öteye gidemeyecek ve öğrenmede kalıc1lıtan bahsedilmeyecektir. Alan yazındaki birçok çalışma da bu bulguyu destekler niteliktedir. Şöyle ki bu çalışmalarda kalıcı öğrenmenin gerçekleşmesi için öğrenmenin ezberden uzaklaşması gerektiğinden bunun yolunun da öğrenilen bilgilerin günlük yaşam ile ilişkilendirme düzeyinin artmasıyla sağlanabileceğinden bahsedilmektedir (Akgün, Çinici, Yıldırım ve Köprübaşı, 2015; Campbell ve Lubben, 2000; Martin, 2009; Pekdağ, Azizoğlu, Topal, Ağalar ve Oran, 2013). Ayrıca fen bilimleri ders kitabında da belirtildiği gibi öğrencilerin varlıkların hareket özelliklerini hepsini bir arada gözlemleyebilecekleri en uygun yer lunaparklardır (Demiray ve Köker, 2017, s.77). Varlıkların hareket özellikleri ile ilgili lunaparktan verilen örneklere bakıldığında, hızlanma hareketine lunaparkta çarpışan araba (\%1); yön değiştirme hareketine gondolun yaptığı hareket (\%1); dönme hareketine dönme dolap (\%42) ve atlıarınca (\%12); sallanma hareketine ise gondolun sallanması (\%3) örneklerinin verildiği görül- 
mektedir. Yavaşlama hareketine ise lunaparktan örnek verilmediği görülmektedir. Lunapark ve parklar özellikle ilkokul çocuklarının daha fazla vakit geçirdiği ve eğlendikleri alanlar olmasına rağmen öğrencilerin lunaparktan kısıtlı örnek vermeleri ilgi çekicidir. Bu durum lunaparkların paralı olmasından ve her öğrencinin sosyoekonomik düzeyinin aynı olmamasından veya ezbere öğrenme yapan öğrencilerin öğrendikleri bilgilerle günlük olayları bağdaştıramadıklarından kaynaklanmış olabilir. Alan yazında yapılan benzer birçok çalışmada da (Doğan, Kırvak ve Baran, 2004; Hürcan ve Önder, 2012; Mengi, 2011; Yılmaz, 2008) öğrencilerin öğrendikleri bilgilerin günlük yaşam ile ilişkilendirme düzeyinin istenilen seviyede olmadığ görülmektedir.

Öğrencilerin "Varlıkların Hareket Özellikleri” konusunda daha çok ders kitaplarında yer alan örnekleri vermelerine rağmen verilen bazı örneklerin ise günlük hayat ile ilişkilendirme düzeyinin yüksek olduğu söylenebilir. Örneğin; ders kitabında yer alan klasik örnekler dışında hılanma hareketine kaplan gören ceylan (\%1), uzaya firlatılan füze (\%2), yıldız kayması (\%2), düşen yağmur damlası (\%1), göktaşı düşmesi (\%1), fare yakalamak isteyen kedi (\%1), yavrusunu kurtarmaya çalışan kuş (\%1), geyik gören çita (\%3), peynir gören fare (\%1); yavaşlama hareketine fişi çekilen mutfak robotunun yavaşlaması (\%1), pili azalan saatte akrebin yavaşlaması (\%1), çamaşır sıkma programının sonuna gelinmesi (\%1); yön değiştirme hareketine duvara ve direğe çarpan top (\%17), kavşaktan dönen araba (\%17), kediyi gören farenin yön değiştirmesi (\%1), çitanın kovaladığı geyik $(\% 1)$, drift atan araba (\%1), ambulans gören arabanın să̆ şeride geçmesi (\%1); dönme hareketine Mevlana (\%3), balerin (\%3), hortum (\%6), semazenlerin dönmesi (\%13), pergeldeki kalemin iğne etrafinda yaptığı hareket (\%1); sallanma hareketine asansörün aşağı yukarı hareketi (\%3), sallanan sandalye (\%6), yelpazenin sallanması (\%2), vurulan boks torbası (\%2), guguklu saat (\%3), bayrağın sallanması (\%3), ipe asilarak sallanan sirkteki gösterici (\%4), saat sarkacı (\%8), kilise çantnın sallanması (\%1), ipe bağladığımı topacın săga sola sallanması (\%1), hactyatmazı ittiğimizde (\%1), sallanan beşik (\%11), sallanan hamak (\%1), trambolinde ziplarken (\%1), klimanın kapă̆ının aşağı yukarı hareketi (\%1), bebeğini ayağında sallayan anne (\%1), deprem aninda evlerin hareketi (\%7) ve ütünün ileri geri hareketi (\%1) örneklerinin verilmesi. Aynı zamanda verilen bu örneklerden öğrencilerin günlük yaşamda meydana gelen bazı olayları iyi gözlemledikleri ve bu gözlemlerini derste öğrendikleri bilgilerle bağdaştırabildikleri sonucuna da ulaşılabilir. Bilge ve Ayvacı (2018) tarafından yapılan ve ortaokul öğrencilerinin 
fen dersinde seçilen bir konuda öğrendikleri bilgileri günlük yaşam ile ne kadar bağdaştırabildiklerini belirlemeye çalıştıkları çalışmanın sonucunda bu bağdaştırmanın istenilen düzeyde olmadığı ancak verilen bazı örneklerin günlük hayat ile ilişkilendirme düzeyinin yüksek olduğu görülmüştür.

Öğrencilerin bir derste veya bir konuda edindikleri bilgileri günlük yaşama aktarma düzeyini belirmeye çalışan alan yazındaki birçok çalışma incelendiğinde, bu çalışmaların sonucunda öğrencilerin konularda yer alan birçok kavramda kavram yanılgısı yaşadıkları görülmüştür (Acet, 2019; Bilge ve Ayvacı, 2018; Canpolat ve Ayyıldız, 2019; Taşdemir ve Demirbaş, 2010). Yapılan çalışmada ise alan yazındaki bu çalışmaların aksine çok az kavram yanılgısına ulaşılmıştır. Örneğin yavaşlama hareketine havalanmaya başlayan uçak (\%1); sallanma hareketine ise tespih sallamak (\%2) örneklerinin verilmesi. $\mathrm{Bu}$ durum ise dikkatsizlikten veya toplumsal yanılgılardan kaynaklanmış olabilir. Şöyle ki piste iniş yapan uçağın yaptığı yavaşlama hareketi sehven havalanmaya başlayan uçak şeklinde ifade edilmiş de olabilir. Sadece bir öğrencinin bu örneği vermesi bu sonucu destekleyebilir. Ayrıca bir öğrencinin sallanma hareketine bilimsel anlamını dikkate almadan toplumumuzda yaygin olan tespih sallama hareketini örnek vermesi toplumun konuşma dilinin bazı öğrencilerde kavram yanılgısı oluşturabileceğini göstermektedir. Kişinin bulunduğu sosyal çevrenin onun bilişsel gelişiminde önemli olduğunu savunan Vygotsky ve alan yazındaki birçok çalışma da bu sonucu destekler niteliktedir (Bilge ve Ayvacı, 2018; Taşdemir ve Demirbaş, 2010; Ülgen, 1997). Çalışmadan elde edilen sonuçlar doğrultusunda şu önerilere yer verilebilir:

1. 2018 Fen Bilimleri Dersi Öğretim Programı öğrenilen bilgilerin günlük hayat ile ilişkilendirilmesinin önemine vurgu yaptığı halde ve fen derslerinin içeriğinin büyük çoğunluğunun günlük hayat ile ilişkili olmasına rağmen ilgili literatür ve bu çalışmanın sonucu bu ilişkilendirmenin istenilen seviyede olmadığını göstermektedir. Dolayısıyla bu duruma yol açan nedenler detaylı bir şekilde araştırılmalı bunun içinde bu programın uygulayıcıları olan öğretmenlerle ve öğrencilerle ayrıntılı görüşmeler yapilabilir.

2. Özellikle soyut düşünme becerisi gelişmemiş olan ilkokul öğrencilerine kavramları somutlaştırmak için soyut kavramların günlük hayat ile ilişkilendirmesi sağlanmalıdır. Bunun için ise öğretmen, sadece ders kitap- 
larında olan örneklerle yetinmeyip öğrencinin doğal çevreyi gözlemlemesi ve bu gözlemlerini derste öğrendiği bilgilerle ilişkilendirmesi için gerekli öğrenme ortamını sağlayabilmelidir.

3. Öğrencilerin derste öğrendikleri bilgileri günlük yaşama transferini kolaylaştırmada önemli bir role sahip olan öğretmenlerin bu konuda öğrencilerine rehberlik edebilmesi için öğretmenlerin lisans eğitiminde de bu ilişkilendirmenin önemine vurgu yapacak seçmeli dersler eklenebilir.

4. Sınav soruları hazırlanırken bu soruların da günlük hayat ile ilişkili problemler olmasına dikkat edilebilir. Böylece öğrenciler günlük hayatlarında daha dikkatli gözlemler yapabilir ve bu gözlemlerini derste öğrendikleri kavramlarla ilişkilendirmek için daha fazla çaba sarf edebilir.

5. Sınıf ortamında verilen kavramlarla ilgili öğrencilerden günlük yaşam örnekleri vermeleri istenerek, öğrencilerde var olan kavram yanılgıları ortaya çıkarılabilir ve bu kavram yanılgılarının ileriki öğrenmeleri olumsuz etkilememesi için anında müdahale edilebilir. 
EXTENDED ABSTRACT

\section{Primary School Students' Association Levels between Daily Life and the Acquired Knowledge on "Motion of Assets" \\ Sümeyye Aydın Gürler \\ Gaziantep University}

Teaching of the complex and abstract concepts that are part of the science curriculum to primary school students is more difficult compared with students in other grades. Hence, it is of significant importance to concretize these concepts. One of the methods for doing so is to associate the abstract concepts with daily life when teaching the students. It has been observed that students are more interested in science courses, that teaching is more effective and that lessons are more enjoyable when concepts in the science course are taught by associating them with daily life (Andree, 2003; Fortus et al., 2005). Thus, the aim of the present study was to determine the association level between daily life and the acquired knowledge on "Motion of Assets" for primary school $3^{\text {rd }}$ grade students.

Case study method was used in the qualitatively designed study. Study data were acquired during the 2019-2020 academic year. Whereas the study group was comprised of 100 third grade students continuing their education at different primary schools at the Nizip district of Gaziantep province. Typical case sampling from among the purposive sampling approaches was used for determining the study group. A questionnaire comprised of five open ended questions prepared by the researcher was used for data acquisition. The study data were analyzed via descriptive analysis method.

It can be stated when the study findings are examined that $3^{\text {rd }}$ grade primary school students are able to associate the fundamental concepts (speeding up, slowing down, changing direction, rotation, swinging) on the "Motion of Assets" subject with daily life. However, it can be understood from the examples given that the level of association is not at the desired level. This is due to the fact that person starting running (\%23), plane lifting off (\%19), car starting up at the green light (\%10) and kicked ball (\%10) (Demiray and Köker, 2017, s. 72) are among the most frequently repeated examples for speeding; 
car approaching red light (\%22), braking car (\%19), bus approaching a stop (\%11) and landing plane (\%10) (Demiray and Köker, 2017, s. 72) are among the most frequently repeated examples for slowing down; Earth rotating around itself (\%16) and rotating whirligig (\%11) (Demiray and Köker, 2017, s. 77) are among the most frequently repeated examples for rotational motion; and that child on a swing (\%76) (Demiray and Köker, 2017 s.76) is the most frequently repeated example for swinging motion which are among examples included in $3^{\text {rd }}$ grade science textbook. It is also observed in many similar studies in literature (Doğan, Kırvak and Baran, 2004; Hürcan and Önder, 2012; Mengi, 2011; Y1lmaz, 2008) that students are not at the desired level with regard to associating their acquired knowledge with daily life. The fact that students give examples in the textbook for "Motion of Assets" despite the large number of similar examples in daily life indicate that some of the acquired information is memorized knowledge. Many other studies in the literature support this finding. Such that, these studies put forth that learning should remain distant to memorizing in order for permanent learning to take place which can be attained by increasing the level of association of acquired knowledge with daily life (Akgün, Çinici, Yıldırım and Köprübaşı, 2015; Campbell and Lubben, 2000; Martin, 2009; Pekdağ, Azizoğlu, Topal, Ağalar and Oran, 2013).

Even though students gave examples from the textbook for "Motion of Assets", it can be stated that the level of association with daily life is higher for various other examples (deer seeing a tiger, rocket launched into space, slowing down of a robot that is turned off, slowing down of the clock hand as the battery loses its power, car taking a corner, rat changing direction after coming across a cat, rotation of ballerinas, whirling dervishes, rocking crib, cuckoo clock). It was observed as a result of the study conducted by Bilge and Ayvac1 (2018) for identifying the level at which secondary school students are able to associate with daily life the acquired knowledge on a selected subject from the science course that the level of association is not at the desired level but that the level of association with daily life is quite high for some of the examples provided.

Related studies in literature carried out for identifying the level at which students are able to transfer their acquired knowledge on a certain subject to daily life reveal that students experience misconceptions in many concepts (Acet, 2019; Bilge and Ayvacı, 2018; Canpolat and Ayyıldız, 2019; Taşdemir and Demirbaş, 2010). Contrary to previous studies, fewer misconceptions 
were observed in the present study. A plane taking off for slowing down or the example of swinging a prayer bead for swinging motion can be indicated as examples of such misconceptions. This may be due to lack of attention or social misconceptions.

\section{Kaynakça / References}

Acet, A. (2019). Ortaokul sekizinci sınföğrencilerinin canllar ve enerji ilişkileri ünitesi kavramlarm günlük yaşamlarna aktarma düzeylerinin belirlenmesi. Yüksek lisans tezi. https://tez.yok.gov.tr/UlusalTezMerkezi/tezSorguSonucYeni.jsp veri tabanından erişildi.

Akgün, A., Çinici, A., Yıldırım, N. ve Köprübaşı, M. (2015). Ortaokul 8. sınıf öğrencilerinin fen ve teknoloji dersi kavramlarını günlük hayata transfer düzeylerinin incelenmesi. Eğitimde Kuram ve Uygulama, 11(4), 1356-1368. https://doi.org/10.17244/eku.536638

Akgün, A., Tokur, F. ve Duruk, Ü. (2016). Fen öğretiminde öğrenilen kavramların günlük yaşamla ilişkilendirilmesi: Su kimyası ve su arıtımı. Adryaman Üniversitesi Ĕgitim Bilimleri Dergisi, 6(1), 161-178. https://doi.org/10.17984/adyuebd.87973

Alkış Küçükaydın, M. (2019). İkkokul öğrencileri fen bilimleri dersinde öğrendikleri bilgileri günlük yaşamlarıyla ne kadar ilişkilendirebiliyor? Bolu Abant İzzet Baysal Üniversitesi Eğitim Fakültesi Dergisi, 19(2), 440-452. https://doi.org/10.17240/aibuefd.2019.19.46660-418986

Andree, M. (2003, August). The everyday-life in science classroom; A study on ways of using and referring to everyday-life. The ESERA Conference in Noordwijkerhout, The Netherlands.

Ash, D. (2004). Reflective scientific sense-making dialogue in two languages: The science in the dialogue and the dialogue in the science. Science Education, 88, 855884. https://doi.org/10.1002/sce.20002

Ayas, A. P. ve Özmen, H. (1998). Asit-baz kavramlarnın güncel olaylarla bütünleştirilme seviyesi: Bir örnek olay çalışması. III. Ulusal Fen Bilimleri Eğitimi Sempozyumu, Trabzon, Turkey.

Aydın, A. (2000). Gelişim ve öğrenme psikolojisi. İstanbul: Alfa Yayınları.

Balkan Kıyıcı, F. ve Aydoğdu, M. (2011). Fen bilgisi öğretmen adaylarının günlük yaşamları ile bilimsel bilgileri ilişkilendirebilme düzeylerinin belirlenmesi. Necatibey Eğitim Fakültesi Elektronik Fen ve Matematik Eğitimi Dergisi (EFMED), 5(1), 43-61. https://doi.org/10.17522/balikesirnef.541641 
Bilge, E. ve Ayvacı, H. Ş. (2018). Ortaokul 7. sınf öğrencilerinin günlük hayat ile ilişkilendirilme düzeylerinin değerlendirilmesi: Maddenin hal değişimi bağlamı. 27. Uluslararası Eğitim Bilimleri Kongresi, Antalya.

Buyruk, B. ve Korkmaz, Ö. (2016). Öğrencilerin fen bilimleri dersine dönük kavramları günlük hayatla ilişkilendirme durumları. On Dokuz Mayıs Üniversitesi Eğitim Fakültesi Dergisi, 35(1), 159-172. https://doi.org/10.33418/ataunikkefd.745381

Büyüköztürk, Ş., Kılıç Çakmak, E., Akgün, Ö. E, Karadeniz, Ş. ve Demirel, F. (2009). Bilimsel araştırma yöntemleri (4. Baskı). Ankara: Pegem Yayıncılık.

Büyüköztürk, Ş., Kılıç Çakmak, E., Akgün, Ö.E., Karadeniz, Ş., ve Demirel, F. (2012). Bilimsel araştırma yöntemleri (11. bask1). Ankara: Pegem Akademi.

Campbell, B. ve Lubben, F. (2000). Learning science through contexts: Helping pupils make sense of everyday situations. International Journal of Science Education, 22(3), 239-252. https://doi.org/10.1080/095006900289859

Canpolat, E. ve Ayyıldız, K. (2019). 8. sını öğrencilerinin fen bilimleri dersi bilgilerini günlük yaşam ile ilişkilendirebilme düzeyleri. Anadolu Üniversitesi Eğitim Fakültesi Dergisi (AUJEF), 3(1), 21-39. https://doi.org/10.17556/jef.50116

Çelikler, D. veKara, F. (2016). Ortaokul5. sını öğrencilerinin "maddenin değişimi" ünitesindeki bilgilerini günlük yaşamla ilişkilendirebilme düzeyleri açısından hazırbulunuşluklarının belirlenmesi. Kafkas Üniversitesi Sosyal Bilimler Enstitüsü Dergisi, 17, 21-39. https://doi.org/10.9775/kausbed.2016.002

Çepni, S. (2007). Araştırma ve proje çalışmalarına giriş. Trabzon: Celepler Matbaacılik.

Çepni, S. (2009). Araştırma ve proje çalışmalarnna giriş (Genişletilmiş 4. baskı). Trabzon: Celepler Matbaacilik.

Çepni, S. (2010). Araştırma ve proje çalışmalarına giriş (Geliştirilmiş 5. baskı). Trabzon: Celepler Matbaacilik.

Demiray, K. ve Köker, Ö. (2017). İlkokul fen Bilimleri 3. sınıf ders kitabı (1. baskı). Ankara: Korza Yayıncilik.

Denscombe, M. (1998) The good research guide. Buckingham: Open University Press

Doğan, S., Kurvak, E. ve Baran, Ş. (2004). Lise öğrencilerinin biyoloji derslerinde edindikleri bilgileri günlük hayatla ilişkilendirebilme düzeyleri. Erzincan Ĕ̈itim Fakültesi Dergisi, 6(1), 57-63. https://doi.org/10.17556/jef.50116

Ekiz, D. (2003). Eğitimde araştırma yöntem ve metodlarna giriş. Ankara: Anı Yayıncılık.

Enginar, I., Saka, A. ve Sesli, E. (2002). Lise 2 öğrencilerinin biyoloji derslerinde kazandıklar bilgileri güncel olaylarla ilişkilendirebilme düzeyleri. V. Ulusal Fen Bilimleri ve Matematik Eğitimi Kongresi, Ankara. 
Fortus, D., Krajcik, J., Charles, D., Marx, R. W. ve Mamlok-Naaman, R. (2005). Design based science and real-world problem-solving. International Journal of Science Education, 27(7), 855-879. https://doi.org/10.1080/09500690500038165

Hürcan, N. ve Önder, İ. (2012, Haziran). İlköğretim 7. smuf öğrencilerinin fen ve teknoloji dersindeöğrendikleri fen kavramlarm günlük yaşamla ilişkilendirmedurumlarmmn belirlenmesi. X. Ulusal Fen Bilimleri ve Matematik Eğitimi Kongresi, Niğde.

İlkörücü-Göçmençelebi, Ş. ve Özkan, M. (2009). İlköğretim altıncı sınıf öğrencilerinin fen bilgisi biyoloji konularını günlük yaşamla ilişkilendirme düzeylerinin başarıya etkisi. Kastamonu Eğitim Dergisi, 17(2), 525-530. https://doi.org/10.17522/balikesirnef.605489

İlkörücü-Göçmençelebi, Ş. ve Özkan, M. (2010). İlköğretim altınc sınuf öğrencilerinin fen bilgisi dersinde öğrendikleri biyoloji bilgilerini günlük yaşamla ilişkilendirme düzeylerini ölçmeye yönelik bir ölçek geliştirme çalışması. Uludağ Üniversitesi Eğitim Fakültesi Dergisi, 23(1), 121-132. https://doi.org/10.17679/inuefd.531733

Kara, F. (2016). Ortaokul 5. sinıf öğrencilerinin fen bilimleri dersinde öğrendikleri bilgileri günlük yaşamlarıyla ilişkilendirebilmelerine yönelik düşünceleri ile fen bilimleri dersindeki başarıları arasındaki ilişki. Erzincan Üniversitesi Eğitim Fakültesi Dergisi, 18(2), 1380-1397. https://doi.org/10.17556/jef.50116

Karasar, N. (2005). Bilimsel araştırma yöntemi. Ankara: Nobel Yayın Dağtım.

Köse, E. Ö. ve Gül, Ş. (2016). Sınıf öğretmeni adaylarının biyoloji bilgilerini günlük yaşamla ilişkilendirme düzeyleri. Amasya Üniversitesi Eğitim Fakültesi Dergisi, 5(1), 84-103. https://doi.org/10.17860/mersinefd.306016

Martin, D. J. (2009). Elementary sciencemethods: A constructivist approach (5th Edition). Belmont, CA: Wadsworth Cengage Learning.

Mengi, F. (2011). Ilköğretim sekizinci smnföğrencilerinin fen ve teknoloji konularmn günlük hayat problemlerinin çözümüne transfer düzeylerinin incelenmesi. Yayımlanmamış Yüksek Lisans Tezi, Çukurova Üniversitesi, Adana.

Mili Ĕgitim Bakanlığı [MEB]. (2018). Fen Bilimleri Dersi Öğretim Programı (llkokul ve Ortaokul 3, 4, 5, 6, 7 ve 8. sinıflar). Ankara: Talim ve Terbiye Kurulu Başkanlığı.

Özmen, H. (2003). Kimya öğretmen adaylarının asit ve baz kavramlarıyla ilgili bilgilerini günlük olaylarla ilişkilendirebilme düzeyleri. Kastamonu Ĕ̆itim Dergisi, 11(2), 317-324. https://doi.org/10.12984/egeefd.310426

Patton, M. Q. (2005). Qualitative research. New York: John Wiley \& Sons, Ltd.

Pekdağ, B., Azizoğlu, N., Topal, F., Ağalar, A. ve Oran, E. (2013). Kimya bilgilerini günlük yaşamla ilişkilendirme düzeyine akademik başarının etkisi. Kastamonu Eğitim Dergisi, 21(4), 1275-1286. https://doi.org/10.24106/kefdergi.2701 
Pınarbaşı, T., Doymuş, K., Canpolat, N. ve Bayrakçeken, S. (1998). Üniversite kimya bölümü öğrencilerinin bilgilerini günlük hayatla ilişkilendirebilme düzeyleri. III. Ulusal Fen Bilimleri Ĕ̆itimi Sempozyumu, Trabzon, Türkiye.

Senemoğlu, N. (2001). Gelişim öğrenme ve öğretim: Kuramdan uygulamaya (3.baskı). Ankara: Gazi Kitabevi.

Strauss, A. ve Corbin, J. (2014). Basics of qualitative research techniques. New York: Sage Publications.

Şimşek, C. L. (Ed.). (2011). Fen öğretiminde okul dışı öğrenme ortamları (1. baskı). Ankara: Pegem Yayincllk.

Taşdemir, A. ve Demirbaş, M. (2010). İköğretim öğrencilerinin fen ve teknoloji dersinde gördükleri konulardaki kavramları günlük yaşamla ilişkilendirebilme düzeyleri. Uluslararast İnsan Bilimleri Dergisi, 7(1), 124-148. https://doi.org/10.23863/kalem.2017.15

Türkoğuz, S. ve Yankayış, K.(2015). Isı ve sıcaklık hakkındaki kavram yanılgılarının günlük yaşama etkileri üzerine öğretmen görüşleri. Bayburt Üniversitesi Ĕgitim Fakültesi Dergisi, 10(2), 498-515. https://doi.org/10.14582/duzgef.645

Ülgen, G. (1997). Eğitim psikolojisi. Ankara: Alkım Yayınevi.

Wellington, J. (2000). Educational research, contemporary issues and practical approaches. London: Continuum.

Yıldırm, A. ve Şimşek, H. (2003). Sosyal bilimlerde nitel araştırma yöntemleri. Ankara: Seçkin Yayinclik.

Yıldırım, A. ve Şimşek, H. (2008). Sosyal bilimlerde nitel araştırma yöntemleri (6. Bask1). Ankara: Seçkin Yayınclik.

Yılmaz, N. (2008). İköğretim altıncı, yedinci ve sekizinci smnflar, lise birinci smnf ve fen bilgisi ögretmen adaylarmm fen bilgisindeki temel bilgilerle günlük hayatı ilişkilendirme becerileri. Yayımlanmamış Yüksek Lisans Tezi, Gazi Üniversitesi, Ankara.

Yiğit, N., Devecioğlu, Y. ve Ayvacı, H. Ş. (2002). İlköğretim fen bilgisiöğrencilerinin fen kavramlarmı günlük yaşamdaki olgu ve olaylarla ilişkilendirme düzeyleri. V. Ulusal Fen Bilimleri ve Matematik Eğitimi Kongresi, Ankara.

\section{Kaynakça Bilgisi / Citation Information}

Aydın Gürler, S. (2021). İlkokul öğrencilerinin “varlıkların hareket özellikleri" konusunda öğrendikleri bilgileri günlük hayat ile ilişkilendirme durumları. OPUS-Uluslararası Toplum Araştırmaları Dergisi, 17(34), 1124-1147. DOI: 10.26466/opus.826004 